\title{
Proposta para Estadiamento do Câncer Colorretal Baseada em Critérios Morfofuncionais. Correlação com Níveis Séricos do Antígeno Carcinoembrionário
}

\author{
Proposal for Colorectal Cancer Stages Based on Morphofunctional Criteria. \\ Correlation with Carcinoembryonic Antigen Levels
}

\author{
DENISE GONÇALVES PRIOLLI ${ }^{1}$; IZILDA APARECIDACARDINALLI ${ }^{2}$; HELENICE PIOVESAN ${ }^{3}$; NELSONFONTANA \\ MARGARIDO $^{4}$, CARLOS AUGUSTO REALMARTINEZ $^{5}$
}

\begin{abstract}
1. Professor Adjunto Doutor Colaborador do Programa de Pós-graduação em Ciências da Saúde da Universidade São Francisco, Bragança Paulista, São Paulo; ${ }^{2}$ Professor Assistente Doutor Colaborador do Programa de Pós-graduação em Ciências da Saúde da Universidade São Francisco, Bragança Paulista, São Paulo. ${ }^{3 .}$ Professor Assistente da Disciplina de Patologia Universidade São Francisco, Bragança Paulista, São Paulo, Brasil. 4. Professor Livre-Docente do Departamento de Cirurgia da Faculdade de Medicina da Universidade de São Paulo, São Paulo, Brasil. ${ }^{5}$ Professor Adjunto Doutor do Programa de Pós-graduação em Ciências da Saúde da Universidade São Francisco, Bragança
\end{abstract} Paulista, São Paulo.

PRIOLLI DG; CARDINALLI IZ; PIOVESAN H; MARGARIDO NF; MARTINEZ CAR. Proposta para Estadiamento do Câncer Colorretal Baseada em Critérios Morfofuncionais. Correlação com Níveis Séricos do Antígeno Carcinoembrionário. Rev bras Coloproct, 2007;27(4): 374-383.

RESUMO: A análise de características morfofuncionais pode ser útil na predição evolutiva do câncer colorretal, especialmente se relacionadas aos níveis séricos de antígeno carcinoembrionário. A pesquisa de instabilidades de cromossomos e genes e alterações da expressão tecidual de proteínas por eles codificadas, tornam atraente a possibilidade do emprego de fatores funcionais como variáveis potencialmente válidas na compreensão do prognóstico do carcinoma colorretal. ${ }^{1}$ Objetivo: Propor estadiamento baseado nas características morfológicas e funcionais do carcinoma colorretal, valorizando o poder prognóstico do antígeno carcinoembrionário. Método: Acompanhou-se 35 pacientes em estágios diferentes da evolução do adenocarcinoma colorretal no período de 2001 a 2007. A medida sérica do antígeno carcinoembrionário foi executada pela técnica de quimioluminescência. Realizou-se estudo anatomopatológico para determinação do grau histológico e estádio TNM, e análise imunohistoquímica para determinação da polarização tecidual do antígeno carcinoembrionário. A classificação morfofuncional foi determinada pela combinação entre grau histológico e polarização do antígeno. $O$ estadiamento morfofuncional baseou-se na associação entre classificação morfofuncional e estadiamento TNM, por pontuação atribuída a cada uma das classificações. As variáveis estudadas foram: CEA sérico, classificação morfofuncional, estadiamento TNM e morfofuncional. Os resultados foram analisados por análise variância, teste de correlação e análise de sobrevivência (Kaplan-Meier e Modelo de Regressão de Cox), adotando-se p>0,05\% para rejeição da hipótese de nulidade. Resultados: A curva de sobrevida no estadiamento morfofuncional apresentou resultados semelhantes aos encontrados no estadiamento TNM. Houve relação entre a nova proposta de estadiamento e o tempo de sobrevida do paciente. Observou-se relação entre o tempo de sobrevida, a classificação morfofuncional e o nível sérico de antígeno carcinoembrionário. Conclusão: $O$ estadiamento morfofuncional é válido para a avaliação prognóstica dos pacientes com adenocarcinoma colorretal, e relaciona-se com os níveis séricos do CEA.

Descritores: Antígeno carcinoembrionário; Imunohistoquímica; Análise de Sobrevida, Estadiamento de neoplasias; Prognóstico; Neoplasia colorretal.

Trabalho realizado no Programa de Pós-graduação em Ciências da Saúde e Disciplina de Anatomia Patológica do Curso de Medicina, da Universidade São Francisco, Bragança Paulista, São Paulo, Brasil.

Recebido em 10/09/2007

Aceito para publicação em 23/10/2007 


\section{INTRODUÇÃO}

O câncer colorretal (CCR) nos Estados Unidos,atualmente, representa a segunda causa de morte por neoplasia entre os homens e a terceira entre as mulheres. ${ }^{2}$ Os índices de mortalidade vêm se alterando lentamente, não obstante os recentes avanços obtidos no diagnóstico precoce e tratamento. ${ }^{3,4}$ No Brasil, a evolução do CCR tem apresentado comportamento semelhante sendo, no momento, a quinta causa mais comum de morte relacionada ao câncer. À semelhança de outros países, sua incidência vem aumentando em comparação a outros tipos de tumores que acometem o aparelho digestório. ${ }^{5}$

A variabilidade dos comportamentos clínico e biológico do CCR tem suscitado grande interesse pelo estudo de fatores que possam estar associados à progressão da neoplasia e, conseqüentemente, ao prognóstico da doença. ${ }^{6,7}$ Estudos têm sido publicados correlacionando variáveis clínicas e histopatológicas ao prognóstico do CCR, mas seus resultados são intrigantes e muitas vezes conflituosos. ${ }^{8,9} \mathrm{O}$ diagnóstico precoce, ${ }^{10}$ a idade,,$^{11}$ localização da neoplasia, ${ }^{12}$ graduação histológica, ${ }^{13}$ grau de penetração na parede intestinal, ${ }^{14}$ comprometimento linfonodal, ${ }^{15}$ produção de muco pela neoplasia, ${ }^{16}$ antígeno carcinoembrionário (CEA), ${ }^{17}$ invasão venosa e neural $^{18}$ são as variáveis mais freqüentemente estudadas, como fatores relacionados ao prognóstico da enfermidade. Estudos foram realizados com o intuito de discriminar o poder prognóstico independente das principais variáveis relacionadas ao CCR. ${ }^{19,20} \mathrm{O}$ consenso dessas publicações revela que os fatores que apresentam associação com a evolução dos doentes são: profundidade de infiltração do tumor na parede intestinal, o comprometimento linfonodal, a presença de metástases e a graduação histológica da neoplasia. ${ }^{18,19}$ Entretanto, as tentativas de avaliação prognóstica baseadas puramente em aspectos morfológicos, apresentam a grave limitação de restringirem-se à observação de um registro microscópico momentâneo da morfologia tumoral, não fornecendo informações sobre o real comportamento biológico do tumor, o qual se encontra relacionado a mecanismos intrínsecos de funcionamento das células componentes daquele tecido. ${ }^{19}$ Recentemente, com a melhor compreensão das alterações genéticas envolvidas na carcinogênese colorretal, a pesquisa de instabilidades de cromossomos e genes, bem como as alterações da expressão tecidual de proteínas por eles codificadas vêm tornando atraente a possibilidade do emprego de fatores funcionais como variáveis potencialmente válidas para a melhor compreensão do prognóstico do CCR. ${ }^{21}$ Com o advento dos métodos de análise indireta da expressão de genes, pela detecção tecidual das proteínas por eles codificadas com técnicas imunohistoquímicas, nova dimensão no estudo da carcinogênese colorretal foi conquistada. A possibilidade da avaliação funcional de antígenos relacionados ao desenvolvimento, crescimento e disseminação do tumor permite verificar sua importância como fator relacionado ao prognóstico da enfermidade. ${ }^{20}$

O CEA, de todos os marcadores tumorais, é o mais freqüentemente utilizado no seguimento de doentes com CCR. Desde a sua descrição por Gold e Freedman, em 1965, ${ }^{22}$ ainda não se encontra bem esclarecido o mecanismo pelo qual o antígeno carcinoembrionário produzido pelas células normais ou neoplásicas da mucosa do trato disgestório atinge a circulação sangüínea. Da mesma forma, existem dúvidas quanto à importância dos níveis elevados do CEA no pré-operatório como variável independente relacionada ao prognóstico da doença. Estudos vêm avaliando o poder prognóstico da quantificação sérica do CEA, correlacionando-o a variáveis morfológicas estabelecidas, representadas pelas diferentes formas de estadiamento, demonstrando associação entre níveis elevados do antígeno e prognóstico desfavorável, entretanto, os resultados são controversos e ainda despertam polêmica. ${ }^{23,24,25}$

Níveis circulantes crescentes de CEA, após a extirpação completa da lesão, podem sugerir recidiva da neoplasia. ${ }^{26}$ Entretanto, existe percentual de CCR escassamente produtores do CEA, que cursam com níveis séricos normais, nos quais a mensuração sangüínea do antígeno encontra-se pouco relacionada a possibilidade de detecção de doença avançada ou recidiva. ${ }^{27}$ Neoplasias com pior grau histológico podem se tornar escassamente produtoras de CEA, em virtude do seu distanciamento da célula normal da mucosa cólica. ${ }^{28}$ Dessa forma, a relação entre níveis séricos do CEA e estádio do CCR permanece incerta ao se considerarem tumores com características histológicas e funcionais distintas. Atualmente, os estudos que correlacionam o CEA ao prognóstico do CCR são dirigidos não apenas a mensuração dos níveis séricos do CEA, mas também a presença do antígeno no tecido tumoral, onde assumem aspectos importan- 
Rev bras Coloproct Outubro/Dezembro, 2007
Proposta para Estadiamento do Câncer Colorretal Baseada em Critérios Morfofuncionais. Correlação com Níveis Séricos do Antígeno Carcinoembrionário Denise Gonçalves Priolli e Cols. tes como capacidade de produção e excreção pela célula neoplásica. ${ }^{27}$

O estadiamento TNM, apesar de ainda ser o melhor e mais utilizado indicador de prognóstico, apresenta-se falho na estimativa da evolução de muitos pacientes, especialmente nos estádios clínicos II e III, dificultando a indicação terapêutica de forma adequada e consensual. ${ }^{29,30}$ Dessa forma, é necessária a incorporação de novos fatores que considerem de forma conjunta aspectos histopatológicos e funcionais.

Proposta de estadiamento que considere características morfológicas e funcionais associadas, baseada em critérios relacionados ao prognóstico do CCR, tais como grau histológico da neoplasia, imunoexpressão e excreção tecidual do CEA, permitiria categorizar estádios baseados não somente nos aspectos histopatológicos, mas também em aspectos funcionais. Esta estratificação, considerando aspectos morfofuncionais, responderia a questão dos diferentes comportamentos de tumores supostamente semelhantes de forma mais precisa.

A partir da combinação de variáveis morfológicas sabidamente reconhecidas como relacionadas ao prognóstico (estadiamento TNM) e variáveis relacionadas à dinâmica funcional do CEA (classificação morfofuncional) seria possível estabelecer a correta estratificação das neoplasias em grupos de comportamentos biológicos semelhantes, permitindo, dessa maneira, maior fidedignidade nas projeções relacionadas ao prognóstico da doença.

O objetivo do presente estudo foi estabelecer proposta de estadiamento do CCR baseado em suas características morfológicas e funcionais, valorizando o poder prognóstico das dosagens séricas do CEA.

\section{MÉTODO}

A realização desse estudo obedeceu todas as etapas previstas pelo Comitê de Ética em Pesquisa da Universidade São Francisco, e as exigências do Conselho de Ética em Pesquisa da Comissão Nacional de Ética em Pesquisa (CONEP) do Ministério da Saúde. (Resolução CNS196/96).

Foram estudados 35 doentes com CCR, classificados em estágios diferentes da evolução da doença (TNM), acompanhados após o diagnóstico da neoplasia no período 2001 a 2007. Não se fez qualquer tipo de seleção quanto à idade, sexo e raça. Foram excluídos os pacientes com CCR com idade menor que
18 anos, pacientes cujo número de linfonodos ressecados fosse menor que 12, ou aqueles que não tiveram como causa mortis o CCR. Doentes que apresentaram doença metastática irressecável no fígado foram submetidos à biópsia local para posterior confirmação histopatológica.

A mensuração do nível de CEA sérico foi realizada pela técnica de quimioluminescência. As amostras sangüíneas foram colhidas por punção venosa imediatamente antes da operação e encaminhadas prontamente ao laboratório de análises.

O estudo anatomopatológico convencional (HE) obedeceu a protocolo previamente elaborado, de maneira que todos os doentes tiveram os mesmos parâmetros estudados. O CCR foi avaliado quanto grau histológico sendo classificados em bem diferenciados, moderadamente diferenciados ou indiferenciados, segundo a extensão de sua aparência glandular. Os tumores produtores de muco foram considerados como indiferenciados, de acordo com a orientação da OMS. Todos os casos estudados foram classificados segundo estadiamento TNM.

A técnica imunohistoquímica foi realizada conforme metodologia anteriormente descrita, empregando-se a técnica de estreptavidina-biotina-peroxidase (ABC) utilizando anticorpo monoclonal anti-CEA (Dako Cytomation. Monoclonal Rabit Carcinoembrionic Antigen. Clone II-7. Código A-115). ${ }^{31}$

Considerou-se positiva a presença do CEA no tecido quando a imunocoloração identificou granulação homogênea acastanhada tanto no tecido normal quanto neoplásico. A análise microscópica das lâminas foi realizada com o auxílio de um microscópio óptico comum, com ajuda de lente objetiva de 100x e com magnificação final de 400x. A leitura de todas as lâminas foi sempre realizada por dois patologistas, de forma consensual, experimentados na interpretação imunohistoquímica.

A polarização do CEA foi avaliada, comparando-se o distanciamento da capacidade de excreção do colonócito normal, ou seja, a alteração da dinâmica funcional avaliada pela perda da direção polarizada do antígeno no tecido neoplásico.

No tecido normal o antígeno foi identificado como uma linha de imunocoloração restrita a membrana ápico-luminal da célula cólica, demonstrando a dinâmica de migração do CEA celular com orientação polarizada, atingindo a região apical da célula (figura 1, foto A). No tecido neoplásico, considerou-se como bem 


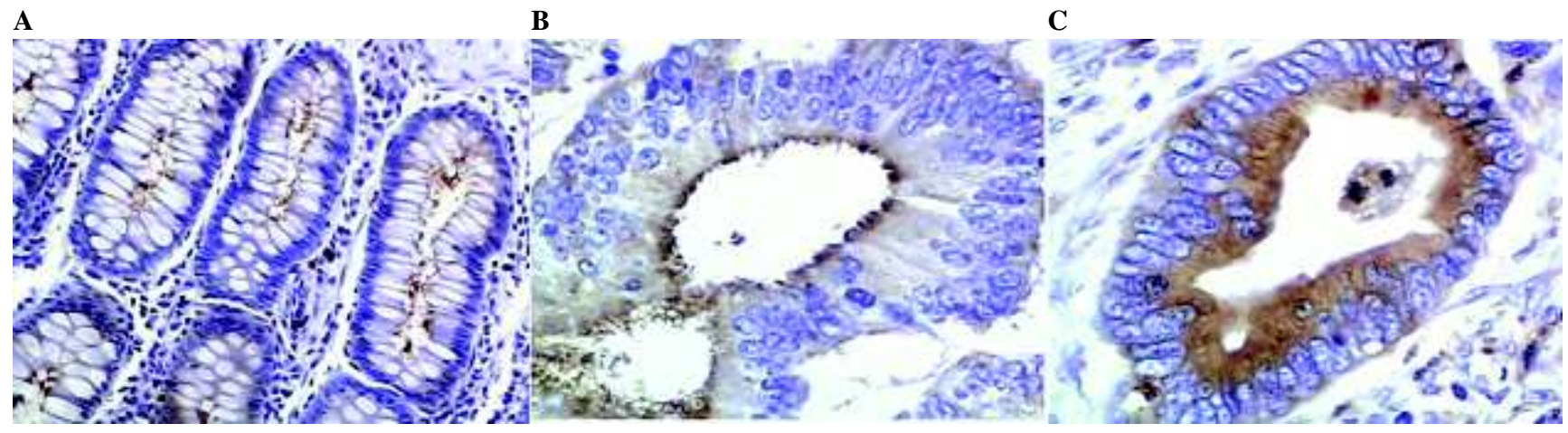

Figura 1 - Polarização celular do CEA tecidual do CEA. A: Polarização celular do CEA no colonócito normal. (Imunohistoquímica para CEA, 100x). B: Carcinoma bem polarizado. C: Carcinoma moderadamente polarizado (Imunohistoquímica para CEA, 400x).

polarizados os carcinomas com manutenção parcial da capacidade de polarização do CEA com acúmulo dos grânulos imunocorados na região ápico-citoplasmática (figura 1, foto B); como moderadamente polarizados, os CCR com distribuição dos grânulos de CEA difusamente imunocorados no citoplasma celular (figura 1, foto C); e como pouco polarizados, aqueles que apresentavam distribuição celular cordonal, pela impossibilidade de se diferenciar o pólo apical do pólo basal celular e neoplasias que, à histologia convencional, representam o padrão mucinoso do CCR.

Os CCR foram agrupados em três classes morfofuncionais de acordo com a funcionalidade e morfologia, baseados na capacidade celular de polarização do antígeno, avaliada pela técnica imunohistoquímica e, o grau histológico, avaliado pela técnica de HE. Carcinomas bem diferenciados e bem polarizados e, moderadamente diferenciados e bem polarizados constituem a classe morfofuncional 1 , enquanto carcinomas moderadamente diferenciados e moderadamente polarizados e, neoplasias bem diferenciadas e moderadamente polarizadas compõem a classe morfofuncional 2; a classe 3 foi constituída por car- cinomas moderadamente diferenciados ou mucoprodutores pouco polarizados e, carcinomas indiferenciados pouco polarizados (Quadro 1).

O estadiamento morfofuncional foi proposto a partir da associação da classificação morfofuncional e o estadiamento TNM, por meio de pontuação atribuída a cada uma das classificações. A somatória igual a 1 (classe morfofuncional 1 (1 ponto) + Estádio TNM 0 (0 ponto), representa o estádio morfofuncional I, enquanto no outro extremo, com somatória igual a 7 (classe morfofuncional 3 (3 pontos) + TNM IV (4 pontos), compõe o estádio IV do estadiamento morfofuncional (Quadro 2).

$\mathrm{Na}$ análise dos resultados obtidos adotou-se valor de $\mathrm{p}$ menor que 5\% para a rejeição da hipótese de nulidade. As variáveis analisadas foram CEA sérico, classe morfofuncional (baseada na polarização celular do CEA e grau histológico da neoplasia), estadiamento TNM, estadiamento morfofuncional e curva de sobrevivência. Os resultados encontrados foram analisados utilizando análise descritiva, análise de variância, regressão linear, curva de sobrevivência de KaplanMeyer, Log-Ranks, Modelo de Cox.

Quadro 1 - Classificação morfofuncional dos CCR.

\begin{tabular}{lcc}
\hline Classe & Grau histológico $($ HE) & Capacidade de polarização (Imunoistoquímica) \\
\hline $\mathbf{1}$ & Bem & Bem \\
$\mathbf{2}$ & Moderadamente & \\
& Bem & Moderadamente \\
$\mathbf{3}$ & Moderadamente & \\
& Moderadamente \\
Pouco & Pouco \\
\hline
\end{tabular}


Rev bras Coloproct

Outubro/Dezembro, 2007
Proposta para Estadiamento do Câncer Colorretal Baseada em Critérios Morfofuncionais. Correlação com Niveis Séricos do

Antígeno Carcinoembrionário

Denise Gonçalves Priolli e Cols.

Quadro 2 - Estadiamento morfofuncional dos CCR.

\begin{tabular}{lccc}
\hline $\begin{array}{l}\text { Estadiamento } \\
\text { morfofuncional }\end{array}$ & Pontuação & $\begin{array}{c}\text { Classe Morfofuncional } \\
\text { (pontuação) }\end{array}$ & $\begin{array}{c}\text { Estádios TNM } \\
\text { (pontuação) }\end{array}$ \\
\hline Estádio I & 1 & $1(1)$ & tis (0) \\
Estádio II & 2 & $1(1)$ & I (1) \\
& 3 & $2(2)$ & \\
Estádio III & 3 & $1(1)$ & \\
& 4 & $2(2)$ & \\
Estádio IV & 5 & $3(3)$ & III (3) \\
& 5 & $2(2)$ & \\
& 6 & $3(3)$ & IV (4) \\
\hline
\end{tabular}

\section{RESULTADOS}

Dos 35 casos acompanhados, $24(68,6 \%)$ se mantêm vivos, houve $9(25,7 \%)$ óbitos e $2(5,7 \%)$ casos se perderam no acompanhamento do $2^{\circ}$ ano. Dezessete casos $(48,6 \%)$ foram classificados como pertencentes à classe morfofuncional 1, 15 (42,9\%), à classe 2 e três $(8,6 \%)$ à classe 3 (Tabela 1$)$. Quanto ao TNM, $65,7 \%$ (23) dos casos pertenciam ao estádio $2 ; 8$ casos $(22,9 \%)$ ao estádio 3 e 4 casos $(11,4 \%)$ ao estádio 4 (Tabela 2).

A taxa de sobrevivência baseada no estadiamentos TNM e morfofuncional demonstrou diferença quanto aos estádios avaliados, respectivamente, $\mathrm{p}=0,001$ e $\mathrm{p}=0,002$ (figura 2). A regressão de Cox demonstrou significância entre o tempo de sobrevida, a classificação morfofuncional e o nível sérico de CEA $(\mathrm{p}=0,002)$

\section{DISCUSSÃO}

O CEA é um dos marcadores tumorais melhor estudados em câncer, sendo rotineiramente utilizado como marcador sérico do carcinoma gastrintestinal, em especial do CCR. ${ }^{23,32}$ Devido à baixa especificidade, não é utilizado como teste diagnóstico, sendo atualmente aplicado na prática clínica no seguimento dos enfermos submetidos ao tratamento cirúrgico do $\mathrm{CCR} .{ }^{33}$ Níveis crescentes do marcador, após a extirpação da lesão, podem sugerir recidiva da neoplasia. Contudo, existe um percentual de tumores colorretais que produzem quantidades pouco expressivas do CEA, determinando níveis séricos baixos, nos quais é pequena a possibilidade de detecção de doença avançada ou recidiva com esse recurso. ${ }^{23,26}$

Há contradições na correlação entre o nível sérico, expressão do CEA no tumor revelado pela análise imunohistoquímica com anticorpos monoclonais anti-CEA e prognóstico das lesões neoplásicas colorretais. $^{27,34}$

A face celular voltada para a luz intestinal apresenta especializações ou microvilosidades relacionadas aos fenômenos de absorção e excreção, próprios da mucosa cólica. As células da mucosa normal do colo sintetizam constantemente o antígeno que migra pelo citoplasma e associa-se à membrana celular, sendo

Tabela 1 - Níveis médios de CEA sérico nas classes morfofuncionais.

\begin{tabular}{cccc}
\hline Classificação morfofuncional & $\mathbf{n}$ & Media CEA sérico (ng/d) & $\mathbf{p}$ \\
\hline 1 & 17 & 9,75 & $0,02 *$ \\
2 & 15 & 17,26 & \\
3 & 3 & 32,70 & \\
\hline
\end{tabular}

Análise de variância, $* p<0,05$. 
Rev bras Coloproct

Outubro/Dezembro, 2007
Proposta para Estadiamento do Câncer Colorretal Baseada em Critérios Morfofuncionais. Correlação com Niveis Séricos do

Antígeno Carcinoembrionário

Denise Gonçalves Priolli e Cols.

Tabela 2: Relação entre estadiamentos e níveis médios de CEA sérico.

\begin{tabular}{lcccc}
\hline Estadiamentos & Estádio & $\begin{array}{c}\text { Média CEA } \\
\text { sérico (ng/dl) }\end{array}$ & $\begin{array}{c}\text { Análise de } \\
\text { variância }\end{array}$ & $\begin{array}{c}\text { Correlação } \\
\text { de Spearman }\end{array}$ \\
\hline \multirow{3}{*}{ TNM } & II & 7,59 & & 0,401 \\
& III & 7,68 & $0,01^{*}$ & $\mathrm{p}=0,01^{*}$ \\
Morfofuncional & IV & 71,67 & & 0,469 \\
& II & 4,15 & $0,01^{*}$ & $\mathrm{p}=0,0001^{*}$ \\
\hline
\end{tabular}

Análise de variância, Correlação de Spearman, *p<0,05.

então eliminado no lume intestinal. ${ }^{35}$ Obedecendo a características de epitélio colunar especializado, proteínas produzidas nas células mucosas do colo têm orientação de direção polarizada no sentido ápico-lateral. Como qualquer outra proteína, o sentido vetorial do CEA no interior da célula também respeita esta orientação. Essa característica das células que compõem a mucosa do intestino grosso é mantida pela constante movimentação compartimentada do CEA produzido nas porções basais das células, que migra progressivamente para o pólo apical para, a partir daí, ser eliminado para o lume intestinal. ${ }^{36}$

No epitélio cólico normal observa-se acúmulo progressivo do CEA no interior do citoplasma de células com menor grau de diferenciação, sugerindo que a incapacidade de polarização do antígeno possa estar relacionada ao menor grau de diferenciação e especialização celular. ${ }^{34,37}$ As células da mucosa cólica migram do interior das criptas para o ápice das vilosidades. À medida que vão se especializando, tornam-se mais diferenciadas quando comparadas às células localizadas no interior das criptas, na zona de epitélio proliferativo. ${ }^{38}$ Estudos demonstraram que o padrão de distribuição tecidual do CEA e os níveis séricos nos doentes com CCR podem estar relacionados com o grau de diferenciação celular do tumor. ${ }^{27,39,40}$ A relação existente entre especialização celular, intensidade e padrão de expressão tecidual vêm fazendo com que o CEA seja utilizado como marcador importante nos estudos que avaliam a dife-
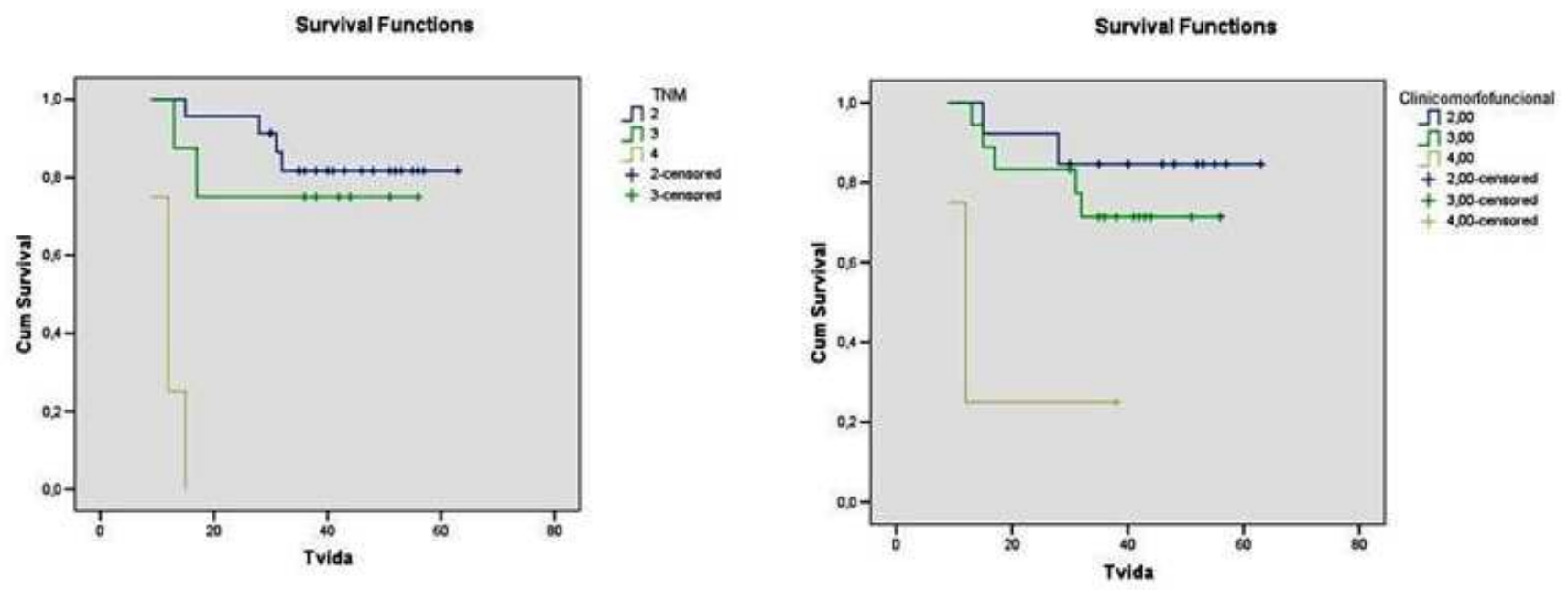

Figura 2 - Curvas de sobrevivência de acordo com os estadiamentos TNM e morfofuncional 
Rev bras Coloproct Outubro/Dezembro, 2007
Proposta para Estadiamento do Câncer Colorretal Baseada em Critérios Morfofuncionais. Correlação com Níveis Séricos do

Antígeno Carcinoembrionário

Denise Gonçalves Priolli e Cols. renciação celular. ${ }^{27,37,38,41}$ Outros autores, entretanto, contradizem esta afirmativa. ${ }^{42,43}$

Tumores bem diferenciados e com padrão de distribuição do tipo apical exibem níveis baixos do CEA sérico, enquanto portadores de tumores moderadamente diferenciados ou indiferenciados com padrão de distribuição citoplasmático apresentam níveis séricos elevados. ${ }^{39}$ Tumores bem diferenciados com intensidade de expressão moderada a intensa, mas com padrão de distribuição do tipo apical, podem cursar com níveis baixos do CEA sérico, pois embora o antígeno esteja presente no tecido, a maior parte dele é eliminada para o lume intestinal. ${ }^{38}$

Demonstrou-se, em estudo in vitro, que a matriz dos adenocarcinomas colorretais é originária de células LISP-I, e que suas subpopulações, LISP-A10 e LISP-E11 possuem características diferentes, epitelial e fibroblástica, respectivamente. As células LISP-A10 são produtoras de moléculas de adesividade intercelular, como o CEA e a desmogleina, enquanto tumores originados na população celular LISP-E11 produzirão de maneira incipiente o CEA, aproximando-se do padrão indiferenciado do CCR. ${ }^{26}$ Esses aspectos indicam que não apenas a característica morfológica celular, como a diferenciação celular, são importantes na determinação dos níveis séricos do CEA, mas também a capacidade das células neoplásicas de produzirem o antígeno. Desta forma, uma classificação que considera fatores morfológicos e funcionais poderia orientar o verdadeiro significado prognóstico dos níveis circulantes do CEA.

No presente estudo, os valores séricos do CEA encontraram-se significantemente mais elevados nas classes morfofuncionais mais avançadas (tabela 1). Desse modo fica reforçada a idéia que o distanciamento da célula neoplásica do colonócito normal, do ponto de vista morfofuncional, propicia o aporte de maiores quantidades do CEA à corrente sanguínea, sugerindo que diferentes expressões fenotípicas encontram-se relacionadas aos níveis circulantes do marcador.

Apesar das controvérsias em relação à validade das dosagens pré-operatórias do CEA, estudos destacam seu valor e mostram associação entre nível préoperatório elevado do antígeno e prognóstico desfavorável. ${ }^{24,27}$ Contradizem estes achados pesquisas mostrando que $14 \%$ a $56 \%$ dos casos de CCR podem cursar com nível sérico de CEA normal. ${ }^{23,44}$ A correlação dos níveis séricos do CEA pré-operatórios com o estádio do carcinoma colorretal permanece polêmica. $\mathrm{Su}-$ geriu-se a relação do CEA como parâmetro prognóstico independente do estádio, ${ }^{11}$ em contraposição àqueles que mostraram a relação dos níveis séricos do CEA em estádios mais avançados da doença neoplásica colorretal. ${ }^{45,46}$

No presente corte, o nível sérico do CEA variou de $0,1 \mathrm{ng} / \mathrm{dl}$ em doente em estádio inicial a 106,0ng/ dl em enfermo portador de metástase hepática. Provavelmente tal associação é dependente do estádio da neoplasia, uma vez que o nível do CEA sérico é também determinado pelas dimensões do tumor primário e lesões metastáticas que representam, na realidade, a massa produtora do antígeno. Além disso, nas neoplasias em estádio avançado, a infiltração a planos profundos facilita o acesso do antígeno à circulação angiolinfática e sua distribuição sistêmica, elevando seus níveis séricos. ${ }^{30,44,47}$ Os resultados obtidos no presente estudo, corroboraram essas afirmativas quando verificouse correlação entre estadiamento TNM e morfofuncional e o nível sérico do antígeno, que encontrou-se elevado nos estádios mais avançados da neoplasia (tabela 2).

Os sistemas de estadiamento do CCR baseiam-se em informações referentes à extensão da doença, sendo importantes no planejamento terapêutico, na avaliação dos resultados obtidos com os tratamentos propostos e no prognóstico. Muitas foram as tentativas em sistematizar o CCR, cabendo a Dukes a mais simples, que combina profundidade de invasão na parede retal e metástase. ${ }^{13}$ Em 1945, a classificação de Dukes foi estendida para o colo e quase 10 anos após, Astler e Coller propuseram nova modificação. ${ }^{14} \mathrm{Em}$ busca de maior acurácia quanto aos resultados obtidos com as estratificações propostas, em 1966 foi publicado o primeiro estadiamento TNM (Tumor, Linfonodo, Metástase) para o CCR. ${ }^{48} \mathrm{O}$ estadiamento TNM é baseado no nível de penetração da parede intestinal (T), no número e localização de linfonodos comprometidos $(\mathrm{N})$, e na presença ou não de metástases à distância (M).

Apesar de ser o estadiamento mais utilizado, o TNM tem acurácia aproximada de $65 \%$, falhando ao estimar a evolução de muitos pacientes. ${ }^{28} \mathrm{~A}$ falha ocorre especialmente nos estádios clínicos II e III, não permitindo consenso em relação a indicação de quimioterapia adjuvante. ${ }^{29}$ Há necessidade de refinamento do estadiamento anatomopatológico por meio da associação de fatores funcionais, com estratificação em grupos que permitam inferências sobre o prognóstico com 
Rev bras Coloproct Outubro/Dezembro, 2007
Proposta para Estadiamento do Câncer Colorretal Baseada em Critérios Morfofuncionais. Correlação com Níveis Séricos do Antígeno Carcinoembrionário Denise Gonçalves Priolli e Cols. melhores índices de acerto. O consenso do Colorectal Working Group, recomenda que o nível sérico do CEA pré-operatório deva ser considerado como fator prognóstico no estadiamento TNM.

No presente estudo, quando se incorporou os aspectos funcionais ao estadiamento TNM, pôde-se demonstrar relação com sobrevida e com os níveis de CEA sérico, com diferença significante entre os estádios morfofuncionais II e III. Foi possível demonstrar que a curva de sobrevida no estadiamento morfofuncional apresentou resultados semelhantes aos encontrados no estadiamento TNM (figura 2). A importância da incorporação de variáveis funcionais na proposta de estadiamento pôde ser bem demonstrada quando se verificou maior correlação entre o nível sérico de CEA e o estadiamento morfofuncional proposto (tabela 2).

Observa-se, à semelhança de outras classificações, que o TNM detecta a extensão clínica da doença avaliada no momento da excisão da lesão, não considerando agressividade, poder de disseminação, resultantes do genótipo do tumor. A análise indireta da expressão de genes, pela detecção tecidual das proteínas por eles codificadas, tal como o CEA, possibilita a avaliação funcional da neoplasia relacionada ao desenvolvimento, crescimento e disseminação do tumor. Desta forma foi possível analisar a importância da dinâmica celular funcional como fator relacionado ao prognóstico da enfermidade, representando, em síntese, as mutações a que as células cólicas foram submetidas. ${ }^{20}$

As evidências encontradas no presente estudo, sugerem que há dois mecanismos responsáveis pelos níveis séricos do CEA no CCR. O primeiro representado pela diferença de produção e excreção nas subpopulações tumorais e perda da capacidade de polarização do CEA (classificação morfofuncional); o segundo, representado pela massa tumoral produtora de antígeno e o grau de invasão na parede intestinal (TNM). A possibilidade de analisar estes dois mecanismos de forma conjunta, origina nova proposta de estadiamento, útil na predição evolutiva da doença, especialmente por se relacionar aos níveis séricos de CEA.

Os resultados encontrados no presente estudo, permitem concluir que o estadiamento morfofuncional é uma estratégia válida para a avaliação prognóstica dos pacientes com câncer colorretal por considerar a dinâmica funcional da célula, além de se relacionar com os níveis séricos do CEA.

ABSTRACT: The analysis of morphofunctions characteristics can be useful in the colorectal cancer evolution, especially if related to the serum carcinoembryonic antigen levels. The research of chromosomes and genes instability, as well as the alterations of tissue protein codified, makes attractive the possibility to use potentially valid functional factors as variables for the understanding of colorectal carcinoma prognosis. Objective: To consider classes based on morphologic and functional colorectal carcinoma characteristics, valuing serum carcinoembryonic antigen levels prognostic power. Method: Third-five patients in different stages of colorectal carcinoma underwent operations from 2001 to 2007. Serum CEA levels, histological grade, tissue CEA cell polarization capacity were analyzed. Colorectal carcinoma was classified according to TNM stages. The morphofunctional classification was determined by the combination between histological grade and antigen polarization, morphofunctional stages have been based in association between morphofunctional classification and stages TNM, by punctuation attributed to each one classification. The results had been analyzed by variance analysis, correlation test and survival analysis (Kaplan-Meier and Cox Model Regression), adopting $\mathbf{p}<\mathbf{0 . 0 5}$. Results: Morphofunctional stages survival curve resulted similar to the joined ones in stages TNM. It had relation between new classification proposed and patient survival time. They had observed relation among survival time, morphofunctional classification and serum carcinoembryonic antigen. Conclusion: Morphofunctional classification is valid for colorectal cancer patient's prognostic evaluation and is related with the serum CEA levels.

Key words: Carcinoembryonic antigen; Immunohistochemistry; Survival Analysis; Neoplasm Staging; Prognosis; Colorectal carcinoma.

\section{REFERÊNCIAS}

1. Pinho MSL. Estadiamento molecular do câncer colorretal: O futuro se aproxima. Rev bras Coloproct 2005;25:27984.

2. Boring CC, Squires TS, Tong T. Cancer statistics 1993. CA Cancer J Clin 1993;43:7-26.
3. Miller SF, Knigth AR. The early detection of colorectal cancer. Cancer 1977;40:945-9.

4. Stower MJ, Hardcastle JD. The results of 1115 patients with colorectal cancer treated over an 8 years period in a single hospital. Eur J Surg Oncol 1985;11:119-23. 
Rev bras Coloproct

Outubro/Dezembro, 2007
Proposta para Estadiamento do Câncer Colorretal Baseada em Critérios Morfofuncionais. Correlação com Níveis Séricos do Antígeno Carcinoembrionário Denise Gonçalves Priolli e Cols.
5. Neves FJ, Mattos IE, Koifman RJ. Mortalidade por câncer de cólon e reto nas capitais brasileiras no período 1980-1997. Arq Gastroenterol 2005;42:63-70.

6. Rich T, Gunderson LL, Lew R, Galdibini JJ, Cohen AM, Donaldson G. Patterns of recurrence of rectal cancer after potentially curative surgery. Cancer 1983; 52:1317-29.

7. Michelassi F, Vanucci L, Ayala JJ, Chappel R, Goldrerg R, Block GE. Local recurrence after curative resection of colorectal adenocarcinoma. Surgery 1990;108:787-93.

8. Kemeny N, Braun DWJr. Prognostic factors in advanced colorectal carcinoma. Importance of lactic dehydrogenase level, performance status, and white blood cell count. Am J Med 1983; 74:786-96.

9. Ponz de Leon M, Sant M, Micheli A, Sacchetti C, Di Gregorio C, Fante R, Zanghieri G, Melotti G, Gatta G. Clinical and pathologic prognostic indicators in colorectal cancer. A population-based study. Cancer 1992;69:626-35.

10. Sanfelippo PM, Beahrs OH. Factors in the prognosis of adenocarcinoma of the colon and rectum. Arch Surg 1972;104:401-6.

11. Cain AS, Longino LA. Carcinoma of the colon in children. J Pediatr Surg.1970; 5:527-32.

12. Wolmark N, Wieand HS, Rockette HE, Fischer B, Glass A, Lawrence W, Lerner N, Cruz AB, Volk H, Shibata H, Evans J, Prager D. The prognostic significance of tumor location and bowel obstruction in Dukes B and C colorectal cancer. Findings from the NSABP clinical trials 1983;198:743-52.

13. Grinnel RS. The grading and prognosis of carcinoma of the colon and rectum. Ann Surg 1939;109:500-33.

14. Dukes CE. The classification of cancer of the rectum. J Pathol 1932;35:323-32

15. Astler VB, Coller FA. The prognostic significance of direct extension of carcinoma of the colon and rectum. Ann Surg 1954;139:846-51.

16. Halvorsen TB, Sein E. Influence of mucinous components on survival in colorectal adenocarcinomas: a multivariate analysis. J Clin Pathol 1988;41:1068-72.

17. Martinez CAR, Priolli DG, Cardinalli IA, Piovesam H, Pereira JA. Importância da correlação entre o padrão de distribuição tecidual do antígeno carcinoembriônico e seus níveis séricos no prognóstico do câncer colorretal. Estudo prospectivo de 50 casos. Rev bras Coloproct 2004;24 (supl.1):90.

18. Knudsen JB, Nilsson T, Sprechler M, Johansen A, Christensen $\mathrm{N}$. Venous and nerve invasion as prognostic factors in postoperative survival of patients with resectable cancer of the rectum. Dis Colon Rectum 1983;26:613-17.

19. Phillips RK, Hittinger R, Blesowsky L, Fry JS, Fielding LP. Large bowel cancer: surgical pathology and its relationship to survival. Br J Surg 1984;71:604-10.

20. Kune GA, Kune S, Field B, White R, Brough W, Schellemberger $\mathrm{R}$, Watson LF. Survival in patients with large-bowel cancer. A population-based investigation from Melbourne Colorectal Cancer Study. Dis Colon Rectum 1990;33:938-46.
21. Pinho MSL. Estadiamento molecular do câncer colorretal: O futuro se aproxima. Rev bras Coloproct 2005;25:279-84.

22. Gold P, Freedman SO. Demonstration of tumor-specific antigens in human colonic carcinoma by immunological tolerance and absorption techniques. J Exp Med 1965;121:439-62.

23. Tate H. Plasma CEA in the post-surgical monitoring of colorectal carcinoma. Br J Cancer 1982;46:323-30.

24. Forones NM, Tanaka M. CEA and Ca 19-9 as prognostic indexes in colorectal cancer. Hepatogastroenteroly 1999;46:905-8.

25. Chapman MAS, Buckley D, Henson DB, Armitage NC. Preoperative carcinoembryonic antigen is related to tumor stage and long-term survival in colorectal cancer. Brit $\mathrm{J}$ Cancer 1998:78:1346-9.

26. Costa CA, Macedo JLS, Reis PEG, Povoa C, Mendes D, Cruz D. O valor do CEA no estadiamento do adenocarcinoma colorretal. Rev Bras Cir 1996;86:171-3.

27. Solimene AC, Carneiro CRW, Melati I, Lopes JD. Functional differences between two morphologically distinct cell subpopulations within a human colorectal carcinoma cell line. Braz J Med Biol Res 2001;34:653-61.

28. Hamada Y, Yamamura M, Hioki K, Yamamoto M, Nagura H, Watanabe K. CEA distribuition pattern and the CEA levels in the peripheral blood in patients with colorectal carcinoma. Cancer 1985;55:136-41

29. Nathanson SD, Shultz L, Tilley B, Kambouris A. Carcinomas of the colon and rectum: a comparative of staging classifications. Am Surg 1986;52:428-33.

30. Gloeckler LA, SEER Cancer statistics review 1973-1991. USDHHS, PHS, NIH, NIH publication no. 1994;94:2789.

31. Martinez CAR, Priolli DG, Cardinalli IA, Piovesan H, Pereira JA, Waisberg J, Margarido NF. Correlação entre o padrão de expressão tecidual e os valores séricos do antígeno carcinoembrionário em doentes com câncer colorretal. Rev bras Coloproct 2006;26:41-53.

32. Chapman MAS, Buckley D, Henson DB, Armitage NC. Preoperative carcinoembryonic antigen is related to tumor stage and long-term survival in colorectal cancer. Brit J Cancer 1998;78:1346-9.

33. Castells A, Bessa X, Daniels M, Ascaso C, Lacy A. Value of postoperative surveillance after radical surgery for colorectal cancer. Dis Colon Rectum 1998;41:714-24.

34. Pagé M, Dalifard I, Bertrand G, Bocquillon PG, Daver A. Immunostaining of colorectal cancer with monoclonal antiCEA antibodies compared to serum and tumor CEA content. Anticancer Res 1986;6:893-6.

35. Schoentag R, Williams V, Kuhns W. The distribuition of blood group substance $\mathrm{H}$ and CEA in colorectal carcinoma. Cancer 1984;53:503-9.

36. Chammas R, Novak EM. Mecanismos de invasão e metástases em câncer colorretal. In: Rossi BM, Nakagawa WT, Ferreira FO, Aguiar Junior S, Lopes A. Câncer de Cólon, Reto e Ânus.1nd ed. São Paulo: Lemar \& Tecmedd Editora; 2004. p.55-62. 
37. Fantini J, Rognoni JB, Culouscou JM, Pommier G, Marvaldi $\mathrm{J}$, Tirard A. Induction of polarized apical expression and vectorial release of carcinoembryonic antigen (CEA) during the process of differentiation of HT29-D4 cells. J Cell Physiol 1989;141:126-34.

38. Shirota K, Minassian H, Jothy S. Protein G-gold immunoelectron microscopy of the colon carcinoma: the effect of tumor differentiation of carcinoembryonic antigen immunostaining. Exp Mol Pathol 1988;49:305-15.

39. Huitric E, Laumonier R, Burtin P, Von Kleist S, Chavonel G. An optical and ultrastructural study of the localization of carcinoembryonic antigen (CEA) in normal and cancerous human rectocolonic mucosa. Lab Invest 1976;34:97-107.

40. Lorenzi M, Vindigni C, Manacci C, Tripodi SA, Iroatulam A, Petrioli R, Franchini G. Histopathological and prognostic evaluation of immunohistochemical findings in colorectal cancer.Int J Biol Markers 1997;12:68-74.

41. Chiquillo Barber MT, Bort Marti I, Navarro Fos S, Perez Bacete M, Esclapez Valero J, Gómez-Ferrer Bayo F. Correlación entre niveles séricos de CEA preoperatorios y tinción inmunohistoquímica del CEA en el carcinoma colorrectal. Rev Esp Enferm Dig 1993;83:249-54.

42. Pihl E, McNaughtan J, Ward HA, Nairn RC. Immunohistological patterns of carcinoembryonic antigen in colorectal carcinoma. Correlation with staging and blood levels. Pathology 1980;12:7-13.

43. Zeng Z, Cohen AM, Urmacher C. Usefulness of carcinoembryonic antigen monitoring despite normal preoperative values in node-positive colon cancer patients. Dis Colon Rectum 1993;36:1063-8.
44. Moertel CG, Schutt AJ, Go VL. Carcinoembryonic antigen test for recurrent colorectal carcinoma. Inadequacy for early detection. JAMA 1978;239:1065-6.

45. Waisberg J, Landman G, Cha ASH, Henriques AC, Gaspar HA, Speranzini MB. Padrão da distribuição tecidual do CEA no carcinoma colo-retal: relação com o nível sérico do CEA e classificação de Dukes. Rev bras Coloproct 2002;22:20-6.

46. Steele G Jr., Ellenberg S, Ramming K, O’Connel M, Moertel $\mathrm{C}$, Lessner H. CEA monitoring among patients in multiinstitucional adjuvant G.I. Therapy protocols. Ann Surg 1982;196:162-69.

47. Sunouchi K, Machinami R, Mori M, Namiki K, Hattori S, Murata Y, Tsuchiya T, Mizuno H, Tadokoro M. Clinical impact of carcinoembrionic antigen messenger ribonucleic acid expression in tumor-draining vein blood on postoperative liver metastasis in patients with colorectal carcinoma: a prospective cohort study. Dis Colon Rectum 2003;46:467-73.

48. UICC Committee on TNM Classification. Malignant tumors of oesophagus, stomach, colon and rectum. Geneve: UICC; 1966.

\section{Endereço para correspondência: DENISE GONÇALVES PRIOLLI}

Rua São Vicente 614 - Bairro Jardim Paulista

Atibaia - SP

12947-390

Fone/fax: (11)4412-7730

E-mail: depriolli@ terra.com.br 